OPEN ACCESS

Edited by:

Yao Zheng,

University of Adelaide, Australia

Reviewed by:

Guoxing Zhu,

Jiangsu University, China

Dongsheng Li,

China Three Gorges University, China

Gao-Ren Li,

Sun Yat-sen University, China

*Correspondence:

Huan Pang

huanpangchem@hotmail.com: panghuan@yzu.edu.cn

Huaiguo Xue

chhgxue@yzu.edu.cn

Specialty section:

This article was submitted to

Electrochemistry,

a section of the journal

Frontiers in Chemistry

Received: 20 April 2019 Accepted: 20 May 2019

Published: 05 June 2019

Citation:

Tang $Y$, Zheng $S$, Xue $H$ and Pang $H$ (2019) Regulation of the $\mathrm{Ni}^{2+}$ Content in a Hierarchical Urchin-Like MOF for High-Performance Electrocatalytic Oxygen Evolution Front. Chem. 7:411.

doi: 10.3389/fchem.2019.00411

\section{Regulation of the $\mathrm{Ni}^{2+}$ Content in a Hierarchical Urchin-Like MOF for High-Performance Electrocatalytic Oxygen Evolution}

\author{
Yijian Tang, Shasha Zheng, Huaiguo Xue* and Huan Pang * \\ School of Chemistry and Chemical Engineering, Guangling College, Yangzhou University, Yangzhou, China
}

The exploitation of efficient non-precious electrocatalysts for the oxygen evolution reaction is extremely important but remains tremendously challenging. Here, we prepared a series of hierarchical urchin-like bimetallic $\mathrm{Ni} / \mathrm{Zn}$ metal-organic framework nanomaterials that served as high-performance electrocatalysts, by regulating the $\mathrm{Ni}^{2+} / \mathrm{Zn}^{2+}$ ratio and using a facile one-step hydrothermal method for the application of the oxygen evolution reaction. The structure of the hierarchical urchin-like microspheres could improve the utilization efficiency of the active species by facilitating the diffusion of gas and reducing the transport resistance of ions, due to its features of a large interfacial area and convenient diffusion channels. In addition, we found that the higher the $\mathrm{Ni}$ ratio was, the better the electrocatalytic performance of these bimetallic metal-organic framework nanomaterials.

\footnotetext{
Keywords: Ni/Zn-MOFs, oxygen evolution reaction, electrocatalysis, hierarchical urchin-like, hydrothermal method
}

\section{INTRODUCTION}

Efficient and sustainable energy storage and conversion devices, such as water splitting, fuel cells, and metal-air batteries, are currently being extensively researched (Yan et al., 2016; Zhao et al., 2016; Xu H. et al., 2018). The oxygen evolution reaction (OER) is a crucial process for many applications of energy conversion (Nai et al., 2017; Yan D. et al., 2017; Zhao et al., 2017; Zhu et al., 2018; Li X. et al., 2019). To date, $\mathrm{RuO}_{2}$ and $\mathrm{IrO}_{2}$ are two standard OER catalysts because of their high catalytic activity (Wu et al., 2017; Zhou et al., 2019). However, the low abundance of $\mathrm{Ru}$ and Ir makes it impossible to utilize them on a massive scale ( $\mathrm{Li}$ et al., 2017; Wang M. et al., 2018; Wang X. et al., 2018). Therefore, extensive attention has been paid to exploring non-noble catalysts with excellent stability and activity (Feng et al., 2016a,b; Yan L. et al., 2017; Wang X. et al., 2018; Xu Y. et al., 2018; Huang et al., 2019; Wang et al., 2019). 
Metal-organic frameworks (MOFs), which are constructed from the coordination of metal ions with organic ligands, are considered as a type of porous versatile material that can be used for a wide range of applications (Yu F. et al., 2016; Liu et al., 2017; Shi et al., 2017; Zheng et al., 2017), including their promising application to the OER (Zheng S. et al., 2018). In practice, the reactive centers of MOFs themselves are regarded as the metal sites at the anodes of MOF. Therefore, transitionmetal based MOFs can be readily applied to OER processes (Yu X. Y. et al., 2016; Zhao et al., 2016). Compared with single metal MOF nanomaterials, bimetallic MOF nanomaterials have displayed excellent electrocatalytic activities because of the synergetic effects between distinct metals. Ni/Fe-based nanosheets (Li F. L. et al., 2019), Ni/Co-based hollow arrays (Song et al., 2019), and Ni/Cu-based nanosheets (Zheng X. et al., 2018) have been reported as good catalysts for the OER. Among these electrocatalysts, many bimetallic MOF catalysts have exhibited exceptional catalytic properties, and many bimetallic systems have shown promising prospects for the application (Lu et al., 2017). However, the stability problem of MOFs may hinder their long-term use and widespread applications (Wang X. et al., 2018). Coincidentally, the urchin-like structure of MOFs could promote the stability of electrocatalysts. This shape can be helpful for improving the utilization efficiency of active species by accelerating gas diffusion and shortening ion transport resistance, owing to its large interfacial area and convenient diffusion channels (Xu et al., 2016; You et al., 2016; Deng et al., 2017).

Herein, a series of hierarchical urchin-like $\mathrm{Ni} / \mathrm{Zn}$ bimetallic MOF nanomaterials, which acted as efficient electrocatalysts for the OER, were prepared by a facile one-step hydrothermal strategy. Through regulation of the $\mathrm{Ni} / \mathrm{Zn}$ ratio, the structure of the hierarchical urchin-like MOF becomes increasingly uniform as the $\mathrm{Ni}$ content increases, resulting in the high electrocatalytic performances of these bimetallic MOF nanomaterials. This work will promote the development of hierarchical urchin-like MOFs as promising electrocatalysts. In addition, the synergistic effects of $\mathrm{Zn}^{2+}$ and $\mathrm{Ni}^{2+}$, which contributed to the high electrochemical performance, should be further explored.

\section{RESULTS AND DISCUSSION}

A series of bimetallic Ni/Zn MOF nanomaterials (K1-K5, where the content of $\mathrm{Ni}$ increases from $\mathrm{K} 1$ to $\mathrm{K} 5$ ) were prepared through a facile hydrothermal method from the coordination of PTA and $\mathrm{Ni}^{2+} / \mathrm{Zn}^{2+}$. As shown in Table S1, the molar ratios of the bimetallic ions $\left(\mathrm{Ni}^{2+} / \mathrm{Zn}^{2+}\right)$ in the MOFs and reactants are demonstrated. This clearly reveals that the $\mathrm{Ni}^{2+} / \mathrm{Zn}^{2+}$ ratio in these MOFs can be easily regulated by adjusting the $\mathrm{Ni}^{2+} / \mathrm{Zn}^{2+}$ ratio in the reactants. Scanning electron microscopy (SEM) and transmission electron microscopy (TEM) were used to show the morphologies and microstructural features of these samples. The low-magnification SEM images present the fairly dispersed urchin-like microspheres (Figure S1). The high-magnification SEM images clearly show the morphologies of the hierarchical urchin-like shapes (Figure 1). As shown in Figure 1e, the K5 sample presents an urchin-like hierarchical microsphere with a size of $4-5 \mu \mathrm{m}$, which is smaller than that of the other samples. This shows that the size of the urchin-like microspheres decreases with increasing $\mathrm{Ni}$ content in the bimetallic $\mathrm{Ni} / \mathrm{Zn}$ MOFs. The urchin-like microspheres are composed of radially oriented nanobelts that become increasingly uniform with increasing $\mathrm{Ni}$ content (Figure 1f).

Moreover, as the $\mathrm{Ni}$ content is increased, the size of the hierarchical urchin-like microspheres become smaller and smaller. The microspheres are more uniform and their nanobelts are longer with increasing $\mathrm{Ni}$ content, which are conducive to ion diffusion (Figure S2, Figures 2a,c,e,g,i). The $\mathrm{Zn}$ and $\mathrm{Ni}$ species are uniformly distributed in each of the K1-K5 samples, which were demonstrated by the elemental mapping (Figures $\mathbf{2 b}, \mathbf{d}, \mathbf{f}, \mathbf{h}, \mathbf{j})$. To further accurately verify the Ni/Zn ratio,

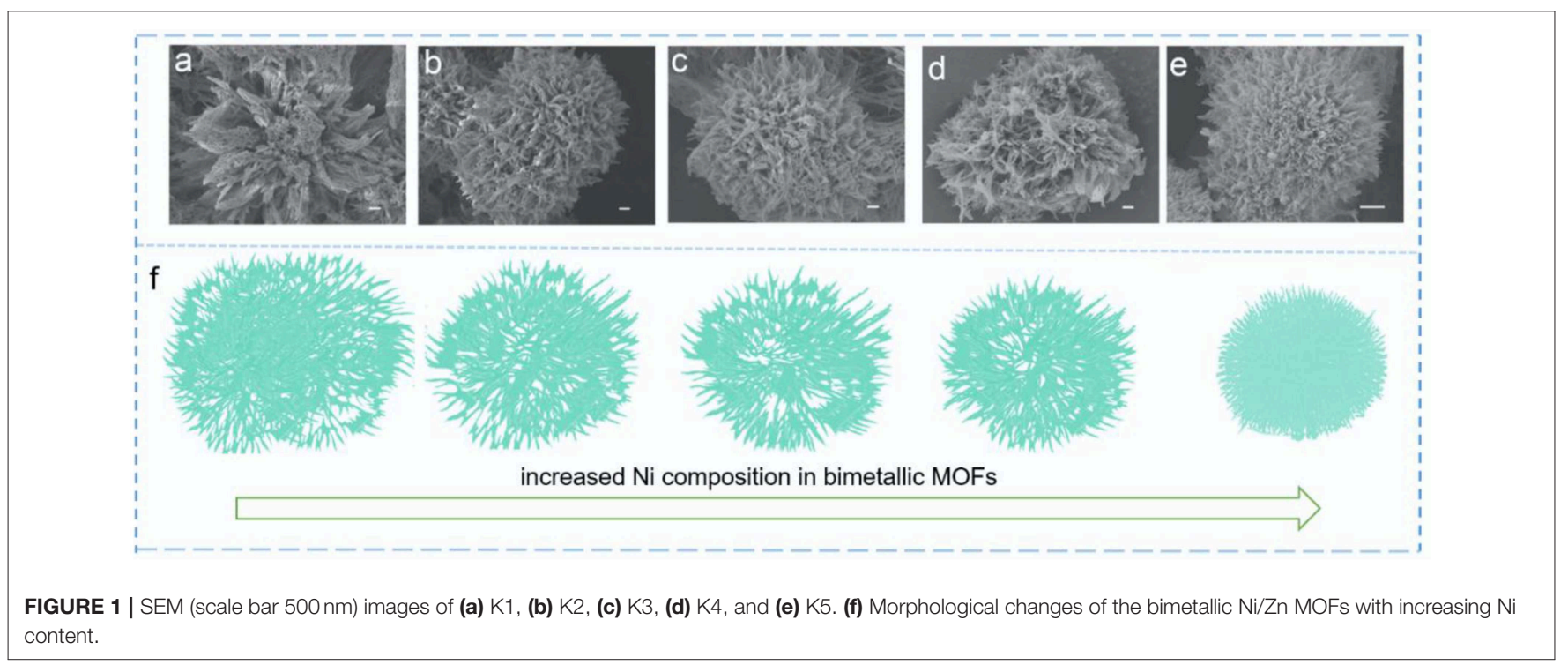



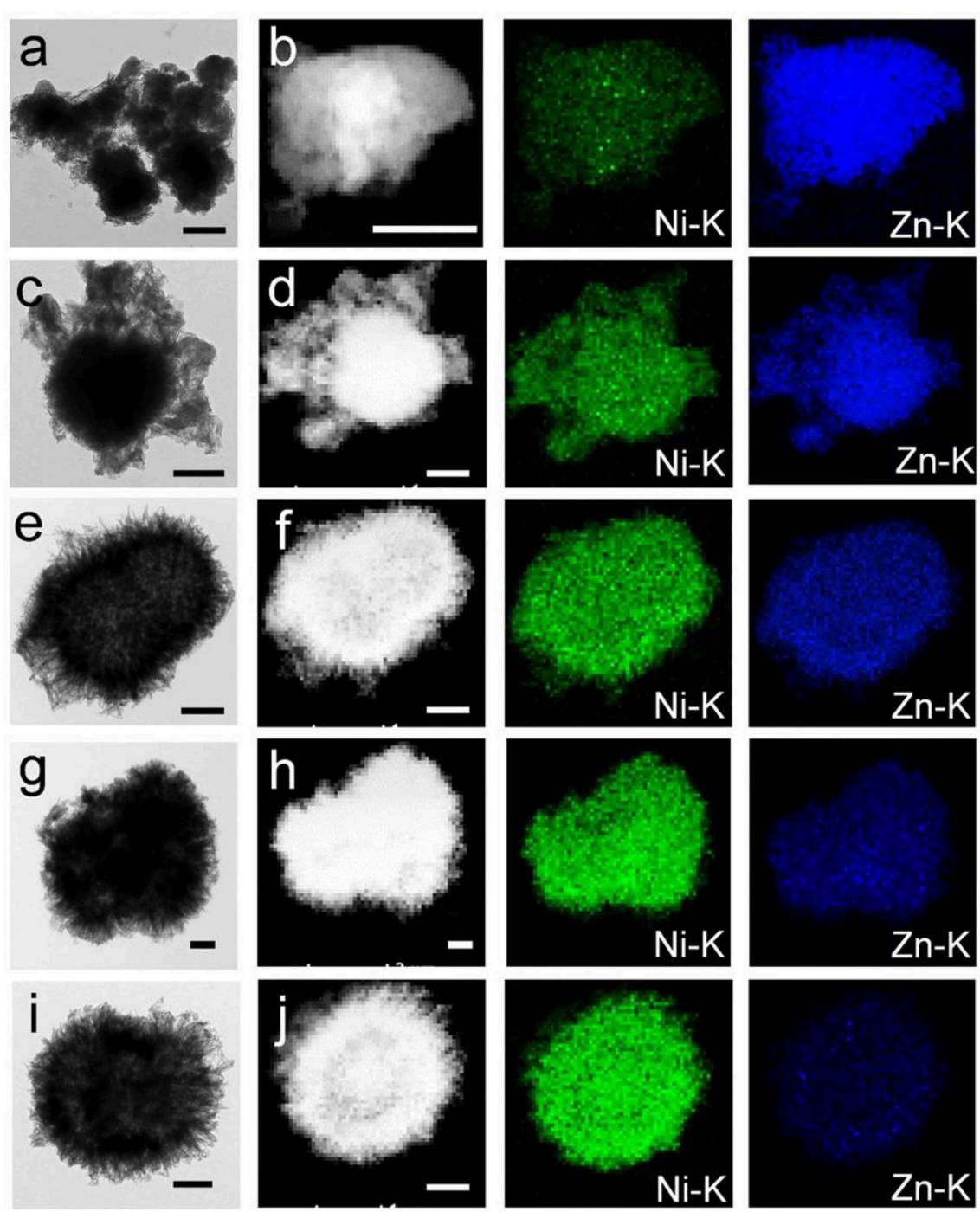

FIGURE 2 | TEM (scale bar $500 \mathrm{~nm}$ ) images of (a) K1, (c) K2, (e) K3, (g) K4, and (i) K5. Elemental mapping (scale bar $100 \mathrm{~nm}$ ) images of (b) K1, (d) K2, (f) K3, (h) $\mathrm{K} 4$, and (j) $\mathrm{K} 5$.

the elemental components of the K1-K5 samples were assessed by using energy-dispersive $\mathrm{X}$-ray spectroscopy (Figure S3). As depicted in Table S1, the $\mathrm{Ni}^{2+} / \mathrm{Zn}^{2+}$ ratio was further confirmed by inductively coupled plasma optical emission spectrometry. The X-ray diffraction (XRD) patterns obviously reveal the crystal and phase structure of the bimetallic Ni/Zn MOFs. As depicted in Figure S4, the XRD patterns are in agreement with previously reported patterns in the literature, and the MOFs have a formula of $\left[\mathrm{Ni}_{3}(\mathrm{OH})_{2}\left(\mathrm{C}_{8} \mathrm{H}_{4} \mathrm{O}_{4}\right)_{2}\left(\mathrm{H}_{2} \mathrm{O}\right)_{4}\right] \cdot 2 \mathrm{H}_{2} \mathrm{O}$ (Yang et al., 2014). The Fourier transform infrared (FTIR) spectra (Figure S5) of these bimetallic MOF nanomaterials is demonstrated. The stretching modes of $\mathrm{OH}^{-}$lead to bands appearing at 3,608 $\mathrm{cm}^{-1}$. A strong peak appears at $3,337 \mathrm{~cm}^{-1}$, which implies the presence of coordinated $\mathrm{H}_{2} \mathrm{O}$ molecules within these bimetallic MOF nanomaterials. Moreover, the band at $1,507 \mathrm{~cm}^{-1}$ results from the stretching modes of the para-aromatic $\mathrm{CH}$ groups. In addition, bands appear at 1,572 and 1,382 $\mathrm{cm}^{-1}$, which arise from the symmetric and asymmetric stretching modes of the coordinated groups $\left(-\mathrm{COO}^{-}\right)$. Although the FTIR spectra of $\mathrm{K} 1-\mathrm{K} 5$ have practically similar peak positions, the separation of the wave number between the symmetric and asymmetric stretching modes of the $-\mathrm{COO}^{-}$groups increases slightly as the $\mathrm{Ni}^{2+}$ ion content increases in the bimetallic MOF nanomaterials, suggesting that the doping of $\mathrm{Ni}$ has some influence on the structures of these bimetallic MOF nanomaterials.

$\mathrm{X}$-ray photoelectron spectroscopy was used to analyze the surface electronic states and the chemical compositions of these bimetallic MOF nanomaterials. Two major peaks $\left(\mathrm{Ni}_{2} \mathrm{p}_{3 / 2}\right.$ and $\mathrm{Ni} 2 \mathrm{p}_{1 / 2}$ ), as shown in Figure S6, were detected in the K1-K5 samples. Combined with the results in Figure S7, the binding energy of $\mathrm{Ni} 2 \mathrm{p}_{3 / 2}$ increases and the binding energy of $\mathrm{Zn} 2 \mathrm{p}_{3 / 2}$ decreases after hybridization (the binding energies of $\mathrm{Ni} 2 \mathrm{p}_{3 / 2}$ 
and $\mathrm{Zn} 2 \mathrm{p}_{3 / 2}$ in the Ni/Zn MOFs are $\sim 855.9$ and $1021.4 \mathrm{eV}$, respectively). From the above, the $\mathrm{Zn}^{2+}$ and $\mathrm{Ni}^{2+}$ have a strong interaction in these $\mathrm{Ni} / \mathrm{Zn}$ MOFs.

The bimetallic MOF nanomaterials in a $1.0 \mathrm{M} \mathrm{KOH}$ electrolyte $\left(\mathrm{N}_{2}\right.$-saturated) were measured for their electrocatalytic properties toward the OER under a standard three-electrode system. Linear sweep voltammetry (LSV) is considered an efficient method to analyze the stability of an electrocatalytic process. As shown in Figure 3A, the LSV curves of the electrodes with $\mathrm{Ni} / \mathrm{Zn} \mathrm{MOF}$ nanomaterials are obtained at $5 \mathrm{mV} \mathrm{s} \mathrm{s}^{-1}$. Notably, the hierarchical urchin-like Ni/Zn MOFs deliver a potential of $\sim 1.45 \mathrm{~V}$ vs. RHE (defined as the onset potential) at $0.1 \mathrm{~mA} \mathrm{~cm}^{-2}$. The overpotential of the $\mathrm{K} 5$ sample is $296 \mathrm{mV}$ at a current density of $10 \mathrm{~mA} \mathrm{~cm}{ }^{-2}$, which is lower than that of the others (K1: $621 \mathrm{mV}, \mathrm{K} 2: 541 \mathrm{mV}, \mathrm{K} 3: 448 \mathrm{mV}, \mathrm{K} 4: 344 \mathrm{mV}$ ). Moreover, the performance evaluation of the OER depends on a significant parameter (a working potential at a current density of $10 \mathrm{~mA} \mathrm{~cm}^{-2}$ ). As shown in Figure 3B, the order of the Tafel slopes is $\mathrm{K} 1>\mathrm{K} 2>\mathrm{K} 3>\mathrm{K} 4>\mathrm{K} 5$. The Tafel slope for the sample of the $\mathrm{K} 5$ catalyst is $82 \mathrm{mV} \mathrm{dec}^{-1}$, which is lower than that of the others. Obviously, these results illustrate that the overpotentials and Tafel slopes of the Ni/Zn MOFs become smaller with increasing Ni content (Figure 3C). The durability of these $\mathrm{Ni} / \mathrm{Zn} \mathrm{MOFs}$ in the test of OER also has an impact on their applications as electrocatalysts for future energy conversion and storage devices. Therefore, a potentiostatic test in a $\mathrm{KOH}$ electrolyte $(1.0 \mathrm{M})$ was carried out. We can see from the I-t curve that $96.2 \%$ of the initial current density is retained after $18000 \mathrm{~s}$ of continuous testing (Figure 3D), which can be attributed to the mass loss of the catalyst on the working electrode during the long-term potentiostatic test.

A typical parameter called electrochemical doublelayer capacitance $\left(\mathrm{C}_{\mathrm{dl}}\right)$ is used to reasonably express the electrochemical surface area. Figure $\mathbf{S 8}$ shows that the K5 sample has a large $\mathrm{C}_{\mathrm{dl}}$ value $\left(12.53 \mathrm{mF} \mathrm{cm}{ }^{-2}\right)$, which is higher than that of the other samples (K1: $7.83 \mathrm{mF} \mathrm{cm}^{-2}, \mathrm{~K} 2: 8.84 \mathrm{mF} \mathrm{cm}^{-2}, \mathrm{~K} 3$ : $9.36 \mathrm{mF} \mathrm{cm}^{-2}$, and $\mathrm{K} 4: 9.88 \mathrm{mF} \mathrm{cm}^{-2}$ ). The higher the $\mathrm{C}_{\mathrm{dl}}$ value is, the greater the roughness of the electrode, and the greater the number of active sites in the nanomaterial, suggesting that the hierarchical urchin-like nanomaterials contribute greatly to the development of the catalytic reaction. Electrochemical impedance spectroscopy illustrates that the sample of K5 exhibits a much smaller charge transfer resistance than the other samples (Figure S9), revealing that a faster charge transfer occurs with increasing $\mathrm{Ni}$ content in $\mathrm{Ni} / \mathrm{Zn} \mathrm{MOF}$ materials. To analyze the surface areas and pore sizes of the hierarchical urchin-like $\mathrm{Ni} / \mathrm{Zn} \mathrm{MOF}$, the isotherms of $\mathrm{N}_{2}$ adsorption-desorption and Barrett-Joyner-Halenda pore size distribution tests have been conducted (Figures S10, S11). These tests present that the higher the $\mathrm{Ni}$ content in the $\mathrm{Ni} / \mathrm{Zn} \mathrm{MOF}$ is, the larger the
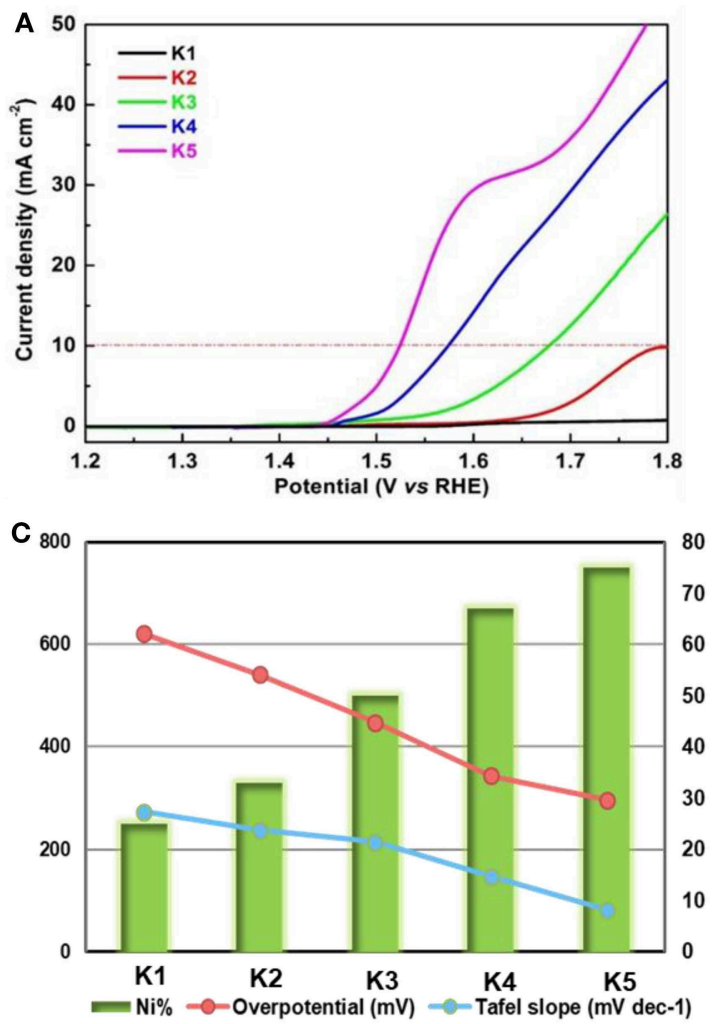

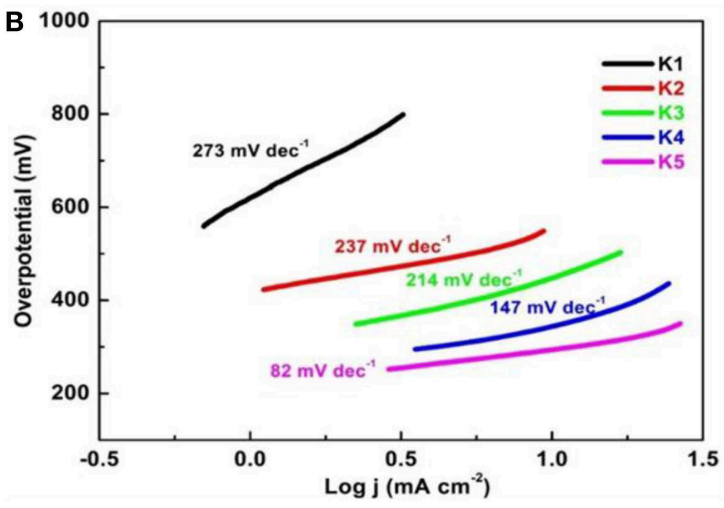

D

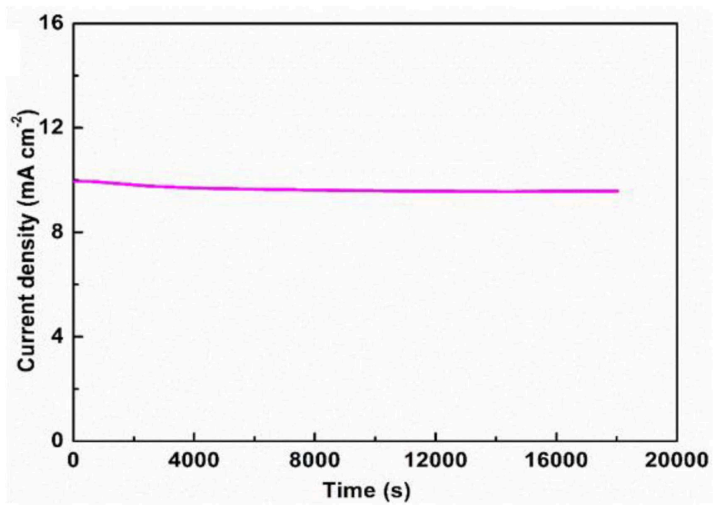

FIGURE 3 | (A) LSV curves for the OER in an $\mathrm{N}_{2}$-saturated $1.0 \mathrm{M} \mathrm{KOH}$ electrolyte at $5 \mathrm{mV} \mathrm{s}^{-1}$; and (B) Tafel slopes of the Ni/Zn-MOF (K1-K5). (C) Intuitive line chart of the samples (K1-K5) for comparison of overpotential and Tafel slopes. (D) Chronoamperometric testing of the hierarchical urchin-like Ni/Zn MOFs for 18,000 s at a static overpotential of $296 \mathrm{mV}$ in an $\mathrm{N}_{2}$-saturated $1.0 \mathrm{M} \mathrm{KOH}$ electrolyte. 
Brunauer-Emmett-Teller (BET) specific surface area, and the greater pore size distribution. The BET specific surface area of the $\mathrm{K} 5$ sample is $113 \mathrm{~m}^{2} \mathrm{~g}^{-1}$, and the pore size distribution of the $\mathrm{K} 5$ sample is approximately $7 \mathrm{~nm}$. This nanomaterial shows better catalytic properties toward the OER because it has a greater number of active sites, which benefit from the high specific surface area and porous structure.

\section{CONCLUSIONS}

Summarily, this study shows a simple and effective hydrothermal strategy to prepare a series of bimetallic Ni/Zn MOFs, which serve as efficient electrocatalysts for the applications of OER. These bimetallic Ni/Zn MOFs exhibited increasing electrocatalytic activity and stability with an increasing $\mathrm{Ni}$ content. The urchin-like microsphere structure can reduce the transport resistance of ions and facilitate the diffusion of gases to improve the utilization efficiency of the active species due to its large interfacial area and convenient diffusion channels. We hope that our work will advance the development of MOFbased electrocatalysts and pave the way for the evolution of bimetallic nanomaterials in a diverse range of energy areas such as water splitting devices, metal-air batteries, fuel cell, and other significant energy systems.

\section{DATA AVAILABILITY}

The raw data supporting the conclusions of this manuscript will be made available by the authors, without undue reservation, to any qualified researcher.

\section{REFERENCES}

Deng, J., Zhang, H., Zhang, Y., Luo, P., Liu, L., and Wang, Y. (2017). Striking hierarchical urchin-like peapoded $\mathrm{NiCo}_{2} \mathrm{O}_{4} @ \mathrm{C}$ as advanced bifunctional electrocatalyst for overall water splitting. J. Power Sourc. 372, 46-53. doi: 10.1016/j.jpowsour.2017.10.062

Feng, J. X., Xu, H., Dong, Y. T., Ye, S. H., Tong, Y. X., and Li, G. R. (2016a). FeOOH/Co/FeOOH hybrid nanotube arrays as high-performance electrocatalysts for the oxygen evolution reaction. Angew. Chemie Int. Ed. 55, 3694-3698. doi: 10.1002/anie.201511447

Feng, J. X., Ye, S. H., Xu, H., Tong, Y. X., and Li, G. R. (2016b). Design and synthesis of $\mathrm{FeOOH} / \mathrm{CeO}_{2}$ heterolayered nanotube electrocatalysts for the oxygen evolution reaction. Adv. Mater. 28, 4698-4703. doi: 10.1002/adma.2016 00054

Huang, D. D., Li, S., Wu, Y. P., Wei, J. H., Yi, J. W., Ma, H.-M., et al. (2019). In situ synthesis of a $\mathrm{Fe}_{3} \mathrm{~S}_{4} / \mathrm{MIL}-53(\mathrm{Fe})$ hybrid catalyst for an efficient electrocatalytic hydrogen evolution reaction. Chem. Commun. 55, 4570-4573. doi: 10.1039/C9CC01433K

Li, F. L., Wang, P., Huang, X., Young, D. J., Wang, H. F., Braunstein, P., et al. (2019). Large-scale, bottom-up synthesis of binary metal-organic framework nanosheets for efficient water oxidation. Angew. Chemie Int. Ed. 58, 7051-7056. doi: 10.1002/anie.201902588

Li, X., Zhu, G., Xiao, L., Liu, Y., Ji, Z., Shen, X., et al. (2019). Loading of $\mathrm{Ag}$ on $\mathrm{Fe}-\mathrm{Co}-\mathrm{S} / \mathrm{N}$-doped carbon nanocomposite to achieve improved electrocatalytic activity for oxygen evolution reaction. J. Alloys Compd. 773, 40-49. doi: 10.1016/j.jallcom.2018.09.269

Li, X. C., Zhang, Y., Wang, C. Y., Wan, Y., Lai, W. Y., Pang, H., et al. (2017). Redox-active triazatruxene-based conjugated microporous

\section{AUTHOR CONTRIBUTIONS}

YT and SZ conducted all the major experiments, designed the study and wrote the manuscript. HX and HP provided valuable inputs for the study's development and helped with manuscript writing. All authors agree to be accountable for the content of the work.

\section{FUNDING}

This work was supported by the National Natural Science Foundation of China (NSFC- 21671170, 21673203, and 21201010), the Top-notch Academic Programs Project of Jiangsu Higher Education Institutions (TAPP), Program for New Century Excellent Talents of the University in China (NCET-13-0645), the Six Talent Plan (2015-XCL-030), and Qinglan Project.

\section{ACKNOWLEDGMENTS}

The authors acknowledge the Priority Academic Program Development of Jiangsu Higher Education Institutions and the technical support we received at the Testing Center of Yangzhou University.

\section{SUPPLEMENTARY MATERIAL}

The Supplementary Material for this article can be found online at: https://www.frontiersin.org/articles/10.3389/fchem. 2019.00411/full\#supplementary-material

polymers for high-performance supercapacitors. Chem. Sci. 8, 2959-2965. doi: 10.1039/C6SC05532J

Liu, C. S., Sun, C. X., Tian, J. Y., Wang, Z. W., Ji, H. F., Song, Y. P., et al. (2017). Highly stable aluminum-based metal-organic frameworks as biosensing platforms for assessment of food safety. Biosens. Bioelectron. 91, 804-810. doi: 10.1016/j.bios.2017.01.059

Lu, X. F., Gu, L. F., Wang, J. W., Wu, J. X., Liao, P. Q., and Li, G. R. (2017). Bimetal-organic framework derived $\mathrm{CoFe}_{2} \mathrm{O}_{4} / \mathrm{C}$ porous hybrid nanorod arrays as high-performance electrocatalysts for oxygen evolution reaction. Adv. Mater. 29:1604437. doi: 10.1002/adma.201604437

Nai, J., Lu, Y., Yu, L., Wang, X., and Lou, X. W. D. (2017). Formation of Ni-Fe mixed diselenide nanocages as a superior oxygen evolution electrocatalyst. $A d v$. Mater. 29:1703870. doi: 10.1002/adma.201703870

Shi, D., Zheng, R., Sun, M. J., Cao, X., Sun, C. X., Cui, C. J., et al. (2017). Semiconductive copper(I)-organic frameworks for efficient light-driven hydrogen generation without additional photosensitizers and cocatalysts. Angew. Chemie Int. Ed. 56, 14637-14641. doi: 10.1002/anie.2017 09869

Song, W., Teng, X., Liu, Y., Wang, J., Niu, Y., He, X., et al. (2019). Rational construction of self-supported triangle-like MOF-derived hollow (Ni,Co) $\mathrm{Se}_{2}$ arrays for electrocatalysis and supercapacitors. Nanoscale 11, 6401-6409. doi: 10.1039/C9NR00411D

Wang, B., Shang, J., Guo, C., Zhang, J., Zhu, F., Han, A., et al. (2019). A general method to ultrathin bimetal-MOF nanosheets arrays via in situ transformation of layered double hydroxides arrays. Small 15:1804761. doi: 10.1002/smll.201804761

Wang, M., Wang, P., Li, C., Li, H., and Jin, Y. (2018). Boosting electrocatalytic oxygen evolution performance of ultrathin $\mathrm{Co} / \mathrm{Ni}-\mathrm{MOF}$ nanosheets via 
plasmon-induced hot carriers. ACS Appl. Mater. Interfaces 10, 37095-37102. doi: $10.1021 /$ acsami.8b13472

Wang, X., Xiao, H., Li, A., Li, Z., Liu, S., Zhang, Q., et al. (2018). Constructing $\mathrm{NiCo} / \mathrm{Fe}_{3} \mathrm{O}_{4}$ heteroparticles within MOF-74 for efficient oxygen evolution reactions. J. Am. Chem. Soc. 140, 15336-15341. doi: 10.1021/jacs.8b08744

Wu, Y. P., Zhou, W., Zhao, J., Dong, W. W., Lan, Y. Q., Li, D. S., et al. (2017). Surfactant-assisted phase-selective synthesis of new cobalt MOFs and their efficient electrocatalytic hydrogen evolution reaction. Angew. Chemie Int. Ed. 56, 13001-13005. doi: 10.1002/anie.201707238

Xu, H., Shi, Z., Tong, Y., and Li, G. (2018). Porous microrod arrays constructed by carbon-confined $\mathrm{NiCo@NiCoO}$ Core@Shell nanoparticles as efficient electrocatalysts for oxygen evolution. Adv. Mater. 30:1705442. doi: 10.1002/adma.201705442

Xu, J., Li, Y., Wang, L., Cai, Q., Li, Q., Gao, B., et al. (2016). High-energy lithiumion hybrid supercapacitors composed of hierarchical urchin-like $\mathrm{WO}_{3} / \mathrm{C}$ anodes and MOF-derived polyhedral hollow carbon cathodes. Nanoscale 8, 16761-16768. doi: 10.1039/C6NR05480C

Xu, Y., Li, B., Zheng, S., Wu, P., Zhan, J., Xue, H., et al. (2018). Ultrathin two-dimensional cobalt-organic framework nanosheets for high-performance electrocatalytic oxygen evolution. J. Mater. Chem. A 6, 22070-22076. doi: $10.1039 /$ C8TA03128B

Yan, D., Li, Y., Huo, J., Chen, R., Dai, L., and Wang, S. (2017). Defect chemistry of nonprecious-metal electrocatalysts for oxygen reactions. Adv. Mater. 29:1606459. doi: 10.1002/adma.201606459

Yan, L., Cao, L., Dai, P., Gu, X., Liu, D., Li, L., et al. (2017). Metalorganic frameworks derived nanotube of nickel-cobalt bimetal phosphides as highly efficient electrocatalysts for overall water splitting. Adv. Funct. Mater. 27:1703455. doi: 10.1002/adfm.201703455

Yan, Y., Xu, H., Guo, W., Huang, Q., Zheng, M., Pang, H., et al. (2016). Facile synthesis of amorphous aluminum vanadate hierarchical microspheres for supercapacitors. Inorg. Chem. Front. 3, 791-797. doi: 10.1039/C6QI00089D

Yang, J., Xiong, P., Zheng, C., Qiu, H., and Wei, M. (2014). Metalorganic frameworks: a new promising class of materials for a high performance supercapacitor electrode. J. Mater. Chem. A 2, 16640-16644. doi: $10.1039 / \mathrm{C} 4 \mathrm{TA} 04140 \mathrm{~B}$

You, B., Jiang, N., Sheng, M., Bhushan, M. W., and Sun, Y. (2016). Hierarchically porous urchin-like $\mathrm{Ni}_{2} \mathrm{P}$ superstructures supported on nickel foam as efficient bifunctional electrocatalysts for overall water splitting. ACS Catal. 6, 714-721. doi: $10.1021 /$ acscatal.5b02193

Yu, F., Zhang, Y., Yu, L., Cai, W., Yuan, L., Liu, J., et al. (2016). All-solid-state direct carbon fuel cells with thin yttrium-stabilized-zirconia electrolyte supported on nickel and iron bimetal-based anodes. Int. J. Hydrogen Energy 41, 9048-9058. doi: 10.1016/j.ijhydene.2016.04.063
Yu, X. Y., Feng, Y., Guan, B., Lou, X. W., and Paik, U. (2016). Carbon coated porous nickel phosphides nanoplates for highly efficient oxygen evolution reaction. Energy Environ. Sci. 9, 1246-1250. doi: 10.1039/C6EE00100A

Zhao, Q., Zhao, M., Qiu, J., Pang, H., Lai, W. Y., and Huang, W. (2017). Facile synthesis of $\mathrm{Mn}_{3}\left[\mathrm{Co}(\mathrm{CN})_{6}\right]_{2} \cdot \mathrm{nH}_{2} \mathrm{O}$ nanocrystals for high-performance electrochemical energy storage devices. Inorg. Chem. Front. 4, 442-449. doi: 10.1039/C6QI00595K

Zhao, S., Wang, Y., Dong, J., He, C., Yin, H., An, P., et al. (2016). Ultrathin metal-organic framework nanosheets for electrocatalytic oxygen evolution. Nat. Energy 1:16184. doi: 10.1038/nenergy.2016.184

Zheng, S., Li, B., Tang, Y., Li, Q., Xue, H., and Pang, H. (2018). Ultrathin nanosheetassembled $\left[\mathrm{Ni}_{3}(\mathrm{OH})_{2}(\mathrm{PTA})_{2}\left(\mathrm{H}_{2} \mathrm{O}\right)_{4}\right] \cdot 2 \mathrm{H}_{2} \mathrm{O}$ hierarchical flowers for highperformance electrocatalysis of glucose oxidation reactions. Nanoscale 10, 13270-13276. doi: 10.1039/C8NR02932F

Zheng, S., Li, X., Yan, B., Hu, Q., Xu, Y., Xiao, X., et al. (2017). Transitionmetal $(\mathrm{Fe}, \mathrm{Co}, \mathrm{Ni})$ based metal-organic frameworks for electrochemical energy storage. Adv. Energy Mater. 7:1602733. doi: 10.1002/aenm.2016 02733

Zheng, X., Song, X., Wang, X., Zhang, Z., Sun, Z., and Guo, Y. (2018). Nickelcopper bimetal organic framework nanosheets as a highly efficient catalyst for oxygen evolution reaction in alkaline media. N. J. Chem. 42, 8346-8350. doi: $10.1039 / \mathrm{C} 8 \mathrm{NJ} 01035 \mathrm{H}$

Zhou, W., Huang, D. D., Wu, Y. P., Zhao, J., Wu, T., Zhang, J., et al. (2019). Stable hierarchical bimetal-organic nanostructures as highperformance electrocatalysts for the oxygen evolution reaction. Angew. Chemie Int. Ed. 58, 4227-4231. doi: 10.1002/anie.201813634

Zhu, G., Xie, X., Li, X., Liu, Y., Shen, X., Xu, K., et al. (2018). Nanocomposites based on $\mathrm{CoSe}_{2}$-Decorated $\mathrm{FeSe}_{2}$ nanoparticles supported on reduced graphene oxide as high-performance electrocatalysts toward oxygen evolution reaction. ACS Appl. Mater. Interfaces 10, 19258-19270. doi: 10.1021/acsami. $8 \mathrm{~b} 04024$

Conflict of Interest Statement: The authors declare that the research was conducted in the absence of any commercial or financial relationships that could be construed as a potential conflict of interest.

Copyright (c) 2019 Tang, Zheng, Xue and Pang. This is an open-access article distributed under the terms of the Creative Commons Attribution License (CC BY). The use, distribution or reproduction in other forums is permitted, provided the original author(s) and the copyright owner(s) are credited and that the original publication in this journal is cited, in accordance with accepted academic practice. No use, distribution or reproduction is permitted which does not comply with these terms. 